\title{
Cervical Cancer: State of the Art and Future Directions
}

\section{Daniel Grossi Marconi*}

Department of Radiation Oncology, Barretos Cancer Hospital, Brazil

Considered a public health problem in the world, cervical cancer mainly affects women in developing countries, where the incidence is up to twice that observed in developed countries. In Brazil, for example, the estimated incidence for 2012 is 17,540 new cases $(17 / 100,000$ women) [1].

The main risk factor associated is HPV infection, which has a large latency period. These features enabled the emergence of quite effective prevention strategies like vaccination and Pap smear campaigns. While developed countries have shown a dramatic reduction in the incidence of this cancer (eg, in the United States the incidence fell from 32.6/ 100,000 women in the late 1940 s to $8.3 / 100,000$ women in the mid1980 [2]), in developing countries the reality is different: the difficulty in ensuring the success of prevention strategies associated with the epidemiological characteristics keep high the incidence of this cancer.

The main stage systems of this cancer are clinical (both FIGO and AJCC), although some researchers advocate the benefit of pretreatment laparotomy. Results of this strategy are not yet convincing, and there is no significant impact on overall survival [3]. Still in the surgical access context, the biopsy of sentinel node has gained ground with encouraging results [4].

When diagnosed at early stages, the tumor is still a matter of controversy as to the most appropriate treatment: radical surgery or radiotherapy. Although in recent years the use of radiotherapy as a single modality has fallen, none of the two approaches seems to have advantage over the other with regard to tumor control and survival [5-7]. The choice is related to the institution, oncological team and characteristics of the lesion and patient. Whatever the strategy, the ideal choice should involve the active participation of a multidisciplinary staff.

When the stage is advanced, the controversy appears to reduce: radiotherapy and chemotherapy have a key role, since the parametrial extension can greatly compromise the outcome of the surgery. Several randomized studies have shown better results adding radiosensitizing chemotherapy to radiotherapy [8-10]. Adding brachytherapy (LDR or HDR) is essential to ensure adequate coverage of tumor dose. However, it is necessary to observe some details to ensure a low toxicity profile. In this context, we highlight the use of three-dimensional technique and the help of other resources such as ultrasound imaging.

\section{Future Directions}

The systemic recurrence is still a big issue in this pathology, and although some progress has occurred in recent years, there is still no permanent solution in sight. The locoregional relapse has been countered with the impending technological development. In this context, the use of image-guided therapy, usage of images with better definition of the target volume (such as MRI) and improvement in softwares of image fusion allow therapeutic optimization: it promotes a better understanding of radio-induced toxicity and dose distribution. In other words, this better understanding of the relationship between the dose distribution and clinical outcomes will allow dose escalation with less toxicity. Furthermore, future studies will definitively establish the role of IMRT and better use of PET in radiotherapy delineation.

\section{References}

1. http://www.inca.gov.br/estimativa/2012/index.asp?ID=5

2. Brinton LA (1992) Epidemiology of cervical cancer--overview. IARC Sci Publ : 3-23.

3. Nelson JH Jr, Boyce J, Macasaet M, Lu T, Bohorquez JF, et al. (1977) Incidence, significance, and follow-up of para-aortic lymph node metastases in late invasive carcinoma of the cervix. Am J Obstet Gynecol 128: 336-340.

4. Di Stefano AB, Acquaviva G, Garozzo G, Barbic M, Cvjeticanin B, et al. (2005) Lymph node mapping and sentinel node detection in patients with cervical carcinoma: a 2-year experience. Gynecol Oncol 99: 671-679.

5. Delgado G, Bundy BN, Fowler WC Jr, Stehman FB, Sevin B, et al. (1989) A prospective surgical pathological study of stage I squamous carcinoma of the cervix: a Gynecologic Oncology Group Study. Gynecol Oncol 35: 314-320.

6. Landoni F, Maneo A, Colombo A, Placa F, Milani R, et al. (1997) Randomised study of radical surgery versus radiotherapy for stage Ib-lla cervical cancer. Lancet 350: 535-540.

7. Landoni F, Maneo A, Colombo A, Placa F, Milani R, et al. (1997) Randomised study of radical surgery versus radiotherapy for stage lb-lla cervical cancer. Lancet 350: 535-540.

8. Peters WA 3rd, Liu PY, Barrett RJ 2nd, Stock RJ, Monk BJ, et al. (2000) Concurrent chemotherapy and pelvic radiation therapy compared with pelvic radiation therapy alone as adjuvant therapy after radical surgery in high-risk early-stage cancer of the cervix. J Clin Oncol 18: 1606-1613.

9. Rose PG, Bundy BN, Watkins EB, Thigpen JT, Deppe G, et al. (1999) Concurrent cisplatin-based radiotherapy and chemotherapy for locally advanced cervical cancer. N Engl J Med 340: 1144-1153.

10. Morris M, Gershenson DM, Eifel P, Silva EG, Mitchell MF, et al. (1992) Treatment of small cell carcinoma of the cervix with cisplatin, doxorubicin, and etoposide. Gynecol Oncol 47: 62-65.
*Corresponding author: Daniel Grossi Marconi, Department of Radiation Oncology, Barretos Cancer Hospital, Brazil, E-mail: dgmarconi@gmail.com

Received May 19, 2013; Accepted May 19, 2013; Published May 22, 2013

Citation: Marconi DG (2013) Cervical Cancer: State of the Art and Future Directions. J Nucl Med Radiat Ther 4: 156. doi:10.4172/2155-9619.1000156

Copyright: ( 2013 Marconi DG. This is an open-access article distributed under the terms of the Creative Commons Attribution License, which permits unrestricted use, distribution, and reproduction in any medium, provided the original author and source are credited. 